\title{
Strategic Perspective Codification of Iran Martial Arts Federation
}

\author{
${ }^{1}$ Shahin Soltanpour*, ${ }^{1}$ Seyed Mohammad Hossein Razavi, ${ }^{2}$ Seyed Nasrolah Sajjadi, \\ ${ }^{3}$ Habib Honari \\ ${ }^{1}$ Department of Sports Management, Faculty of Sports Science, University of Mazandaran, Babolsar, Iran. \\ ${ }^{2}$ Department of Sports Management, Faculty of Sports Sciences, University of Tehran, Tehran, Iran. \\ ${ }^{3}$ Department of Sports Management, Faculty of Sports Sciences, Allameh Tabataba'i University, Tehran, Iran.
}

Submitted 13 September 2017; Accepted in final form 10 January 2018.

\begin{abstract}
Background. The current study aimed at codifying the strategic perspective of Iranian federation of martial arts sport. Objectives. The current study aimed at investigating the negative consequences of the use of social networks at the workplace from the viewpoint of the employees of the sports and youth departments. Methods. The current strategic study was conducted based on a combination of sequential explanatory methods. The statistical population of the study consisted of 138 individuals including the chairman, vice-chairman, and the secretary of the Iran Martial Arts Federation, the officials of the internal committees of the federation, the directors of provincial boards of martial arts, the directors of the styles (associations, committees, and groups), and the members of the Strategic Council of the Federation of which 43 individuals were selected to participate in the study using the Cochran formula. The data were collected through interviews, open and closed questionnaires, and Delphi method. The employed questionnaire had 27 items: seven in strengths, five in weaknesses, seven in opportunities, and six in threats. The validity of the research tool was assessed by 15 sport management experts and martial arts experts and its reliability was also confirmed by Cronbach's alpha coefficient for strengths $(\alpha=796)$, weaknesses $(\alpha=0.704)$, opportunities $(\alpha=0.845)$, and threats $(\alpha$ $=0.774$ ). To prioritize the strengths, weaknesses, opportunities, and threats, the Friedman test was used to determine the strategic position of the federation through weighing and the severity of each factor. In order to formulate strategies, SWOT analysis and pairwise comparison of ST, WO, SO, and WT were employed. Finally, the quantitative strategic planning matrix (QSPM) was used to prioritize strategies. Results. The strategic position of the Iran Martial Arts Federation in the SO region was codified. Conclusions. Based on the current study results, three SO, two WO, two ST, two WT, and nine strategies were presented to clarify the vision of the Iran Martial Arts Federation.
\end{abstract}

\section{KEY WORDS: Federation, Martial Arts, Strategic Plan, SWOT}

\section{INTRODUCTION}

Today, sports organizations, similar to nonsports organizations, are exposed to environment change and global developments, and challenge for their own specific issues (1). In professional sport, exhibiting the highest competence is the main goal of athletes and to achieve this goal, managers, instructors, sports experts, academies, and federations play a crucial role (2). In Iran, the federations as the highest official authorities in sport arena, possess a very crucial place and due to the relationship with international sport agencies, need a decent management with special planning and among the currently active federations, the Iran Martial Arts is the most important sport federation, which has a great number of audience and plays a major role in the development of sports and physical education in Iran. The Martial Arts Federation of the Islamic

*. Corresponding Author:

Shahin Soltanpour, $\mathrm{PhD}$

E-mail: shahinsoltanpoor@yahoo.com 
Republic of Iran was established in 1989 with the aim of retention, development, and spread of the talents of martial arts athletes in Iran and international arenas and with the support of the sport organizations and efforts made by the related management, and in accordance with international standards, attracts and trains martial arts athletes all throughout the territory of Iran, and now the outcome of such efforts is 86 martial arts styles in the form of associations, committees, and martial arts groups working under the supervision of the Iran Martial Arts Federation (3).

Many sports researchers and experts believe that one of the most important sectors and priorities in high-level sports is to launch an integrated and organized system for sport management (1). Sport organizations, according to their own internal and external environment and use of strategic planning, to varying degrees need innovative and reinforcement strategies, as well as development and research, and try to meet their goals while dealing with these changes using attraction plans and based on competitive situation (4). The sport federations and club teams by the use of strategic management and long-term plans try to develop athletes' capabilities from the younger ages among which Iran Martial Arts Federation is not an exception. The strategic plan forces managers to focus on wider organizational issues rather than short-term matters; in fact, the purpose of strategic planning is to help organizations to obtain competitive advantages (5).

As soon as the codification of strategic plans, organizations should try to examine, identify, and classify the strengths, weaknesses, opportunities, and threats found in the internal and external environment of the organization, which can lead to its growth or destruction (6). It is impossible to make a plan without considering analyses and even if planning is performed, its fulfillment would not be possible $(7,8)$. Following the efforts made in this regard in 2013 in Isfahan Province on a Strategic Sport Development Program based on the SWOT model, Baldhi reported that the martial arts board of Isfahan Province, in addition to indices such as fostering talents throughout the province, strengthening the participation of athletes in martial arts events, improving the general appearance of martial art, development of nationwide and provincial communications, and the establishing a marketing system for martial arts at provincial level, suffers from threats, which one of the major reasons for such unfavorable situation is the lack of a strategy to develop martial arts in Isfahan Province (9).

Khabiri et al., noted that the main barriers to financial support are not limited to the management structure of the Taekwondo industry and attracting sponsors, but environmental barriers also play an important role in failing to develop financial support. The most important obstacles identified root in Iran's economic structure, some legal problems, government ownership of clubs, the structure and manpower of the Taekwondo industry, marketing management, planning of Taekwondo tournaments, and Taekwondo industry facilities (10). Khabiri and Memari found that the most important factor in Iran's taekwondo is the significant growth of participation in international events, and also showed that this situation is the best achievement for the presence of the Taekwondo team heroes as individuals who are potentially capable for the coaching and managing Iran's Taekwondo Team. The most important weakness of Iran's taekwondo industry can be the lack of efficiency and poor management, and the most important risk is inappropriate use of sponsors and inadequate information and general knowledge about this sport (11).

The British Karate Council provided a strategic plan, from 2014 to 2018, which led to the guidance, development, and promotion of people to karate in all ages, and evaluation of the ability of interested people, leadership, justification, support and care, humility, hard work, respect, diversity, and the equality were among its strategies (12). For this purpose, the researcher's main goal was to identify the strengths, weaknesses, opportunities, and threats of the Iran Martial Arts Federation, and formulate a strategic plan of the federation using the viewpoint of experts and elites in order to help the Martial Arts Federation to achieve its goals with a management relied on that strategic plan.

\section{MATERIALS AND METHODS}

Participants. The participants consisted of 138 individuals including the chairman, vicechairman, and the secretary of the Iran Martial Arts Federation, the officials of the internal 
committees of the federation, the directors of provincial board of martial arts, the heads of the styles (associations, committees, and groups) and the members of the Strategic Council of the Federation of which 43 individuals were selected using the Cochran formula to participate in the study.

Methodology and Research Tools. The current strategic and field experiment study had descriptive-analytical design. This was a sequential research performed with a combination of qualitative and quantitative methods. In the qualitative stage, semi-structured and conceptual interviews were used in order to explain and outline the conceptual components of the study. The data were collected through interviews, open and closed questionnaires, and Delphi method. The employed questionnaire had 27 items: seven in strengths, five in weaknesses, seven in opportunities, and six in threats. The validity of the tool was evaluated and confirmed by 15 sport managers as well as martial arts experts and their reliability by Cronbach's alpha coefficient for strengths $(\alpha=796)$, weaknesses $(\alpha=0.704)$, opportunities $(\alpha=0.845)$, and threats $(\alpha=0.774)$.

Statistical Analysis. Friedman test was employed to prioritize the strengths, weaknesses, opportunities, and threats, and weighing were used to determine the strategic position of the federation. To formulate strategies, SWOT analysis was used and ST, WO, SO, and WT were compared pairwise, and the severity of each factor was determined. Finally, the quantitative strategic planning matrix (QSPM) was used to prioritize strategies. In the descriptive analyses, SPSS version 18 was used to calculate frequency, percentage, and mean.

\section{RESULTS}

In the current study, $90.7 \%$ of the subjects were male and $9.3 \%$ female. Most of them $(46.5 \%)$ had a master's degree, $7 \%$ were $\mathrm{PhD}$ holder, $37.2 \%$ had a bachelor's degree, $4.7 \%$ associate degree, and $4.7 \%$ diploma. However, $63 \%$ had a degree in physical education and $37 \%$ had non-physical education, but had experience in martial arts.

The participants were within the age range of 20 to 50 years. In addition, $34.9 \%$ of the subjects had 11-15 years of experience in sports management and $25.6 \%$ had a history of management in martial arts, indicating the long experience of the study subjects. In terms of strengths of the Iran Martial Arts Federation, nine items were identified that, after the final weighing, the terms "variety of martial arts and multiple styles" and "holding managerial meetings" in the SWOT analysis had respectively the highest and the lowest priorities (Table 1).

Regarding the weaknesses of the Iran Martial Arts Federation, five items were identified, which after the final weighing, the items " lack of budget and credits and dependence of the federation on the state budget" and "lack of research on martial arts" had respectively the highest and lowest priorities based on SWOT analysis (Table 2).

Table 1. Prioritization of the Strengths of the Iran Martial Arts Federation Based on Friedman Test

\begin{tabular}{|c|c|c|c|}
\hline Item & Strength & Mean & Priority \\
\hline 1 & S1 -Decent management and proper arrangement at the federation level & 5.83 & 2nd \\
\hline 2 & S2- The presence of special forces experts in the federation & 4.72 & 6th \\
\hline 3 & $\begin{array}{l}\text { S3 - The scientific potentials and technical experiences of coaches and referees, and their } \\
\text { geographical distribution in Iran }\end{array}$ & 4.52 & 7th \\
\hline 4 & S4- Holding managerial meetings & 3.30 & 9th \\
\hline 5 & S5 - Variety of marital arts and multiple styles & 6.81 & 1st \\
\hline 6 & S6- Organizing regular domestic tournaments for different age groups & 5.29 & 4 th \\
\hline 7 & S7 - Access to instructions and regulations for different styles & 4.17 & 9th \\
\hline 8 & S8 -Access to various specialized committees at the federation level & 4.74 & 5th \\
\hline 9 & S9- Honor history of Iranian athletes in Asian and global events & 5.59 & 3th \\
\hline
\end{tabular}

Table 2. Prioritization of the Weaknesses of the Iran Martial Arts Federation Based on Friedman Test

\begin{tabular}{|llcc|}
\hline Item & Weakness & Mean & Priority \\
$\mathbf{1}$ & W1-Lack of budget and credits and dependence of the federation on the state budget & 3.73 & $1 \mathrm{st}$ \\
$\mathbf{2}$ & W2- Lack of equipment and exclusive halls in Iran & 3.28 & $2 \mathrm{nd}$ \\
$\mathbf{3}$ & W3- Inappropriate marketing and revenue generation system of the federation & 3.06 & $3 \mathrm{rd}$ \\
$\mathbf{4}$ & W4-Inappropriate statistical information system in the Association of Martial Arts Athletes & 2.53 & 4 th \\
$\mathbf{5}$ & W5- Lack of research on martial arts & 2.40 & 5 th \\
\hline
\end{tabular}

In terms of opportunities of the Iran Martial Arts Federation, seven items were identified that, after the final weighing, the items "access to high and potential talents for the development of 
martial arts in Iran" and "development of specialized journals in Iran" had respectively the highest and lowest priorities based on SWOT analysis (Table 3 ).

In terms of threats of the Iran Martial Arts Federation, six items were identified that, after the final weighting, "lack of sponsors and sport supporters" and "lack of interest in some families to take their children to do martial arts" had respectively the highest and lowest priorities based on SWOT analysis (Table 4).

The total scores of this matrix (2.78) were above 2.5 (Table 5) indicating that the federation is strong in terms of internal factors; in other words, the strengths of the Iran Martial Arts Federation were superior to its weaknesses.

Table 3. Prioritization of the Opportunities of the Iran Martial Arts Federation Based on Friedman Test

\begin{tabular}{|llcc|}
\hline Item & Opportunity & Mean & Priority \\
$\mathbf{1}$ & O1 - Access to high and potential talents for the development of martial arts in Iran & 5.42 & 1 st \\
$\mathbf{2}$ & $\begin{array}{l}\text { O2 - The positive attitude of the Ministry of Sports and Youth and the National Olympic Committee } \\
\text { toward martial arts }\end{array}$ & 3.30 & 6 th \\
$\mathbf{3}$ & $\begin{array}{l}\text { O3 - Appropriate interactions between the federation and governmental/ non-governmental } \\
\text { organizations and institutions }\end{array}$ & 3.64 & 4 th \\
$\mathbf{4}$ & O4 - The development of specialized journals in Iran & 2.83 & 7 th \\
$\mathbf{5}$ & 05- Possibility for women to wear hijab in domestic and international tournaments & 3.37 & 5 th \\
$\mathbf{6}$ & O6- Winning medals in martial arts in Asian and global events & 4.91 & $2 \mathrm{nd}$ \\
$\mathbf{7}$ & O7 - Join of some styles at the Sport Acord and the Olympic Council of Asia & 4.53 & $3 \mathrm{rd}$ \\
\hline
\end{tabular}

Table 4. Prioritization of Threats of the Iran Martial Arts Federation Based on Friedman Test

\begin{tabular}{|llcc|}
\hline Item & Threat & Mean & Priority \\
$\mathbf{1}$ & T1 - Poor reflection of martial arts achievements by national media & 3.62 & Third \\
$\mathbf{2}$ & T2 - High prevalence of illegal drugs and supplements consumption in Iran & 3.80 & Second \\
$\mathbf{3}$ & T3 - Lack of financial sponsors and sport supporters & 4.62 & First \\
$\mathbf{4}$ & T4 - Activity of some non-licensed clubs & 2.97 & Fifth \\
$\mathbf{5}$ & T5 - The activity of non-specialist coaches in some clubs and teams & 3.29 & Fourth \\
$\mathbf{6}$ & T6 -Lack of interest in some families to take their children to do martial arts & 2.67 & Sixth \\
\hline
\end{tabular}

Table 5. Internal Factors of the Iran Martial Arts Federation

$\begin{array}{lccc}\text { Strength } & \text { Weight } & \text { Rank } & \begin{array}{c}\text { Rank X } \\ \text { Weight }\end{array} \\ \text { Variety of martial arts and availability of multiple styles } & 0.09 & 4 & 0.36 \\ \text { Decent management system and proper arrangement at federation level } & 0.09 & 4 & 0.36 \\ \text { Honor history of Iranian athletes in Asian and global events } & 0.08 & 4 & 0.32 \\ \text { Organizing regular domestic tournaments for different age groups } & 0.08 & 4 & 0.32 \\ \text { Access to various specialized committees at the federation level } & 0.07 & 4 & 0.28 \\ \text { The presence of special forces experts in the federation } & 0.07 & 3 & 0.21 \\ \text { The scientific potentials and technical experiences of coaches and referees, and their } & 0.06 & 3 & 0.18 \\ \text { geographical distribution in Iran } & 0.05 & 3 & 0.15 \\ \text { Access to instructions and regulations for different styles } & 0.04 & 3 & 0.12 \\ \text { Holding management assemblies and meetings } & \text { Weight } & \text { Rank } & \text { Rank X } \\ \text { Weakness } & 0.09 & 1 & \text { Weight } \\ \text { Lack of budget and credits and dependence of the federation on the state budget } & 0.09 & 1 & 0.09 \\ \text { Lack of equipment and specific halls in Iran } & 0.08 & 1 & 0.09 \\ \text { Inappropriate marketing and revenue generating system in the federation } & 0.06 & 2 & 0.12 \\ \text { Inappropriate statistical information system in the Association of Martial Arts Athletes } & 0.05 & 2 & 0.10 \\ \text { Lack of research on martial arts } & 1 & 2.78 \\ \text { Total } & & \end{array}$

On the other hand, the evaluation of the external factors of the Iran Martial Arts Federation (Table 6) showed that the total score of this matrix (2.53) was above 2.5, which indicated that the federation also had opportunities in external factors. In other words, it represented the dominance of opportunities over the threats of the federation.

\section{Internal and External Analyses}

The final score of the internal and external factor assessment matrix revealed that the strategic position of the Iran Martial Arts Federation was in the SO region. Since the position or point obtained was located in the aggressive zone, the measures tend to promotion and 
development, and the federation was on the way to take advantage from the

strengths, which in turn provided opportunities.

Table 6. External Factors of the Iran Martial Arts Federation

\begin{tabular}{|c|c|c|c|}
\hline Opportunity & Weight & Rank & $\begin{array}{c}\text { Rank X } \\
\text { eight }\end{array}$ \\
\hline Access to high and potential talents for the development of martial arts in Iran & 0.10 & 4 & 0.4 \\
\hline Winning medals in martial arts in Asian and global events & 0.09 & 4 & 0.36 \\
\hline Join of some styles at the Sport Accord and the Olympic Council of Asia & 0.08 & 4 & 0.32 \\
\hline $\begin{array}{l}\text { Appropriate interaction between the federation and governmental/ non-governmental } \\
\text { organizations and institutions }\end{array}$ & 0.08 & 3 & 0.24 \\
\hline Possibility for women to wear hijab in domestic and international tournaments & 0.07 & 3 & 0.21 \\
\hline $\begin{array}{l}\text { The positive attitude of the Ministry of Sports and Youth and the National Olympic } \\
\text { Committee toward martial arts }\end{array}$ & 0.06 & 3 & $0 / 18$ \\
\hline The development of specialized journals in Iran & 0.06 & 3 & 0.18 \\
\hline Threat & Weight & Rank & $\begin{array}{c}\text { Rank X } \\
\text { eight }\end{array}$ \\
\hline The absence of financial sponsors and sport supporters & 0.10 & 1 & 0.09 \\
\hline High prevalence of illegal drugs and supplements consumption in Iran & 0.09 & 1 & 0.09 \\
\hline Poor reflection of martial arts achievements by national media & 0.09 & 1 & 0.09 \\
\hline The activity of non-specialist coaches in some clubs and teams & 0.07 & 2 & 0.14 \\
\hline Activity of some non-licensed clubs in Iran & 0.06 & 2 & 0.12 \\
\hline Lack of interest in some families to take their children to do martial arts & 0.05 & 2 & 0.10 \\
\hline Total & 1 & & 2.53 \\
\hline
\end{tabular}

\section{Assessing Internal and External Factors of Matrix Final Score}

In Table 7, while the strengths, weaknesses, opportunities, and threats of the federation are pointed out, matching strategies are also described.

The followings were recommended:

Nine strategic development basics regarding different styles of martial arts in Iran were: empowerment of human resources, effective communication, and participation in international forums, expansion of martial arts among women and successful participation in Asian and global events, expanding infrastructures, establishing a marketing and revenue management system in the federation, the interaction with the Islamic Broadcasting Organization of Iran, the widespread reflection of the activities of martial arts by the national media, extensive supervision of martial arts events in Iran, engagement and consultation with financial sponsors and sports supporters, performing research and creating databased on the information of athletes, coaches, referees, and places in martial arts.

\section{DISCUSSION}

As noted in Table 1 and 2, the Iran Martial Arts Federation has the strengths such as decent management system, appropriately organizing the federation, activity of experts in the federation, scientific potentials and technical experiences of coaches and referees, and their geographical distribution in Iran, holding meetings and assemblies, the diversity of martial arts and different styles, holding regular tournaments for various age groups, access to special rules for the various styles, and access to various specialized committees at the federation level; therefore, the federation enjoys the honors of Iranian martial arts athletes in Asia and the world. It is suggested to improve the strengths and promote the performance.

Nevertheless, the Iran Martial Arts Federation faces some weaknesses such as lack of budget and credit and being dependent on the state budget, lack of specialized equipment and halls in Iran, inappropriate marketing and revenue generation system in the federation, inappropriate statistical information system for the Association of Martial Arts Athletes, and lack of research on martial arts. Integrated studies on the strategic analysis of various sports in Iran, despite potentials for the development of sport, lack of human resources, lack of bylaw and regulations in sport institutions, lack of a regular monitoring and appraisal system, lack of financial resources, lack of specialized researches and articles about sports, lack of adequate standard spaces, lack of equipment and facilities were the most important internal barriers, and on the other hand, increase in equipment prices, lack of sufficient financial resources, and lack of advertising and media attention were considered as external barriers to Iran`s sport (1, $5,6)$. Therefore, a suitable strategy should be adopted by the Iran Martial Arts Federation on the basis of these issues. 
Table 7. The Matrix of Strengths, Weaknesses, Opportunities, and Threats of the Iran Martial Arts Federation

\begin{tabular}{|c|c|c|}
\hline Weakness & Strength & Internal factors \\
\hline $\begin{array}{l}\text { W1- Lack of budget and credits } \\
\text { and dependence of the federation } \\
\text { on the state budget } \\
\text { W2- Lack of equipment and } \\
\text { exclusive halls in Iran } \\
\text { W3- Inappropriate marketing and } \\
\text { revenue generation system of the } \\
\text { federation } \\
\text { W4- Inappropriate statistical } \\
\text { information system for the } \\
\text { Association of Martial Arts } \\
\text { Athletes } \\
\text { W5- Lack of research on martial } \\
\text { arts }\end{array}$ & $\begin{array}{l}\text { S1- Variety of martial arts and multiple } \\
\text { styles } \\
\text { S2- Decent management and proper } \\
\text { arrangement at the federation level } \\
\text { S4- Organizing regular domestic } \\
\text { competitions for different age groups } \\
\text { S5- Access to various specialized } \\
\text { committees at the federation level } \\
\text { S6- The presence of experts in the } \\
\text { federation } \\
\text { S7- The scientific potentials and } \\
\text { technical experiences of coaches and } \\
\text { referees, and their geographical } \\
\text { distribution in Iran } \\
\text { S8- Access to instructions and } \\
\text { regulations for different styles } \\
\text { S9: Holding managerial meetings and } \\
\text { assemblies }\end{array}$ & \\
\hline $\begin{array}{l}\text { Using environmental } \\
\text { opportunities to decrease internal } \\
\text { weaknesses } \\
\text { Expansion of infrastructures and } \\
\text { facilities of martial arts across the } \\
\text { country } \\
\text { W1, W2, O1, O2, O4, O6 } \\
\text { Creating and establishing a } \\
\text { marketing and revenue } \\
\text { generation system in the } \\
\text { federation } \\
\text { W1, W3, O2, O3, O4, O7 }\end{array}$ & $\begin{array}{l}\text { Benefiting from internal strengths to } \\
\text { use environmental opportunities } \\
\text { Development of different styles of } \\
\text { martial arts in S1, S2, S4, S6, S7, S8, } \\
\text { O1, O2, O4, O5, O6, O7 } \\
\text { 2. Empowering human resources, and } \\
\text { effective communication and } \\
\text { participation in international sports } \\
\text { associations } \\
\mathrm{S} 2, \mathrm{~S} 3, \mathrm{~S} 5, \mathrm{~S} 6, \mathrm{~S} 9, \mathrm{O} 2, \mathrm{O} 3, \mathrm{O} 6 \\
\text { 3. Expanding martial arts among } \\
\text { women to take place in domestic and } \\
\text { international/Asian events }\end{array}$ & $\begin{array}{l}\text { Opportunities } \\
\text { O1- Access to high and potential talents for the } \\
\text { development of martial arts in Iran } \\
\text { O2- Winning medals in martial arts in Asian and } \\
\text { global events } \\
\text { O3- Join of some styles at the Sport Acord and } \\
\text { the Olympic Council of AsiaO4- Appropriate } \\
\text { interaction between the federation and } \\
\text { governmental/non-governmental organizations } \\
\text { and institutions } \\
\text { 05- Possibility for women to wear hijab in } \\
\text { domestic and international } \\
\text { O6- Positive attitude of the Ministry of Sports } \\
\text { and Youth and the National Olympic Committee } \\
\text { toward martial arts } \\
\text { O7- The development of specialized martial arts } \\
\text { journals in the country }\end{array}$ \\
\hline WT Strategies & ST Strategies & (T) Threats \\
\hline $\begin{array}{l}\text { Decreasing internal weaknesses } \\
\text { and avoiding environmental } \\
\text { threats } \\
\text { 1. Interaction and consultation } \\
\text { with financial sponsors and sport } \\
\text { supporters } \\
\text { 2. Performing research activities } \\
\text { and establishing a statistical } \\
\text { information system for athletes, } \\
\text { coaches, and places in martial arts } \\
\text { T6W4, W5, T2, T4, T5 }\end{array}$ & $\begin{array}{l}\text { Using internal strengths to decrease } \\
\text { and eliminate environmental threats } \\
1 \text {. Interaction with Islamic } \\
\text { Broadcasting Organization of Iran and } \\
\text { the reflection of martial arts activities } \\
\text { by the national media } \\
\text { 2. Extensive supervision of the martial } \\
\text { art styles and places in Iran } \\
\text { S2, S5, S6, S7, S8, S9, T2, T4, T5, T6 }\end{array}$ & $\begin{array}{l}\text { T1- The absence of sponsors and sport supporters } \\
\text { T2- High prevalence of illegal drugs and } \\
\text { supplements consumption in Iran } \\
\text { T3- Poor reflection of martial arts achievements } \\
\text { by national media } \\
\text { T4- The activity of non-specialist coaches in } \\
\text { some clubs and teams } \\
\text { O7- The access to specialized martial arts } \\
\text { journals in the country }\end{array}$ \\
\hline
\end{tabular}

The results showed that due to the identified opportunities such as access to high and potential talents for the development of martial arts in Iran and winning medals in martial arts in Asian and global events, it is necessary to provide and codify a strong database to identify talents in the Iran Martial Arts Federation. It is also essential to share information among provinces and make a link among affiliated organizations to reflect the results; major step was taken toward the presence of a new generation of martial arts in Iran, which is acknowledged by various sport sectors in Iran $(1,6,8,13)$. In the current research, the fundamental development of different styles of martial arts in Iran and its promotion in women's sector, and successful participation in Asian and global events were the first and second priorities, which the federation should consider them in programming. 
In this regard, by promotion and implementation of a strategic plan, China could leave the fourth place of the 1996 Atlanta Olympics and win the third place of 2000 Sydney Olympics, and second rank of the 2004 Athens Olympics; Also, Australia could leave the seventh place of Atlanta Olympics and get the fourth place of Sydney and Athens Olympics (5). The results of the current research indicated that the Iran Martial Arts Federation faces a challenge of a poor reflection of martial arts activities by the national media. Mass media have a significant effect on changing attitudes and behavior of people toward doing sport, but this effect does not fit with the needs of the community, because they prefer to promote the championship sport due to economic benefits (14). Due to the lack of coordination among sport organizations, as well as the mass media, the above said seems problematic in sports.

Therefore, it is necessary to take the essential measures in this regard and consider the need for appropriate federation interactions with governmental and non-governmental organizations and institutions that was one of the identified opportunities. The results of the study indicated that the Iran Martial Arts Federation deals with high prevalence of drugs and supplements. It is reported that financial incentives, public expectations, and achieving a success encouraged many athletes not to adhere to their health, and attain a win in any cost (15). The results of the study indicated that the Iran Martial Arts Federation faces challenges such as budget deficits and its dependency on the state budget, as well as the inadequacy of the marketing and revenue generation system. The Iranian support structure is similar to those of many sports federations, but it is expected that due to the positive attitude of the Ministry of Sports and Youth and the National Olympic Committee toward martial arts, to provide a suitable marketing system for the Iran Martial Arts Federation. As noted in Tables 3 and 4, the Iran Martial Arts Federation has opportunities such as the presence of high talent and potentials for the development of martial arts in Iran, the positive attitude of the Ministry of Sports and Youth and the National Olympic Committee toward martial arts, the proper interactions of the federation with governmental/ non-governmental organizations, the existence of specialized martial arts journals in Iran, the possibility for women to wear hijab in domestic and overseas events, winning medals in martial arts in Asian and global events, join of some styles at the Sport Acord and OCA, and threats such as poor reflection of the martial arts activities by national media, high prevalence of illegal drugs consumption in Iran, the lack of financial sponsors and supporters for martial arts, Activity of some non-licensed clubs in Iran, the activity of non-specialist coaches in some clubs and teams, and lack of interest in some families to take their children to do martial arts; it is worthy to take advantage from these opportunities in the best manner to overcome threats.

Interaction and consultation with financial sponsors and supporters, interaction with the Islamic Republic of Iran Broadcasting Organization, the broad reflection of martial arts activities by national media, and the establishment of a marketing and revenue management system in the federation were among the strategies noted in the current study, which can raise financial problems by attracting financial sponsors and supporters and creating a system of revenue generation can decrease the federation's dependency on the state budget.

Also, broadcasting of sport events by the national media familiarizes the various strata of society with the various fields covered by the federation. Among other strategies obtained, empowerment of human resources, effective communication and participation in international sport communities can be mentioned, which in addition to promoting the scientific and technical experts, can encourage athletes to take place in Asian and global tournaments.

\section{CONCLUSION}

The results of the study showed that the development of infrastructure and martial arts facilities in Iran is one of the main strategies of the federation, which should be provided by providing required funds and facilities. Finally, two strategies for performing research activities and the creation of a statistical information system for athletes, instructors, judges, and places of martial arts and extensive oversight on the activity of martial art styles and places in Iran are the governing and supervisory tools of the federation, which the federation chainman, heads of styles and heads of provincial boards of martial arts can take into account in long and short terms to attain predetermined goal. 
As a whole, the Islamic Republic of Iran's Martial Arts Federation with its appropriate strategy (SO region) can continue its development and by implementing strategies can overcome its weaknesses, inadequacies, and external environment threats, and as one of the developed federations in Iran can move ahead to gain high ranks at the international level. Thus, it is suggested that the Iran Martial Arts Federation by analyzing the measures taken to implement the strategies, can maximize the strengths and opportunities and decrease the environmental weaknesses and threats.

\section{APPLICABLE REMARKS}

- Fundamental development of different styles of martial arts in Iran;

- Expansion of martial arts for women and encourage them to take place successfully in Asian and global tournaments;

- Interaction and consultation with financial and sports sponsors;

- Interaction with the Islamic Republic of Iran Broadcasting Organization and the broad reflection of martial arts activities by the national media;

- Establishment and deployment of a marketing and revenue generation system in the federation;
- Empowerment of human resources and effective communication and participation in international sports associations;

- Development of infrastructures and facilities of martial arts in Iran;

- Performing research activities and establishing a statistical information system for athletes, instructors, judges, and places in martial arts;

- Extensive supervision of the activities of martial art styles and places in Iran.

- The mission of the Iran Martial Arts Federation is relied on the following items:

- The familiarity of the various generations with different covered styles, increasing the number of male and female audience in Iran, and investing at the basic range, promotion of the scientific and technical instructors and coaches, and effective presence in Asian Federations, and taking place in in Asian and global events.

- The vision of the Iran Martial Arts Federation was determined by the Delphi method:

- The Iran Martial Arts Federation is developed at the national level with an appropriate rank and holding special position at international tournaments.

\section{REFERENCES}

1. Hadian H, Boroumand MR, Amirnejad S, Najafi M. Obstacles Facing the Iranian Basketball Academy. Annals of Applied Sport Science. 2016;4(3):41-50. doi: 10.18869/acadpub.aassjournal.4.3.41

2. Williams AM, Reilly T. Talent identification and development in soccer. J Sports Sci. 2000;18(9):657-667. doi: 10.1080/02640410050120041 pmid: 11043892

3. Iranian Martial Art Federation. Federation Introducing and its history 2017 Iran: Iranian Martial Art Federation; 2017 [cited 2018]. Available from: https://bit.ly/2IrCysp.

4. Slack T, Thibault L, Hinings B. Strategic Planning for Nonprofit Sport Organizations: Empirical Verification of a Framework. J Sport Manag. 1994;8(3):218-233. doi: 10.1123/jsm.8.3.218

5. Khosravizadeh E, Hamidi M, Yadollahi J, Khabiri M. Iran NOC Strengths, Weaknesses, Opportunities, Threats, Issues and Challenges it confronts. J Sport Manag. 2009;1(1):19-35.

6. Najafi M, Safania AM, Boroumand MR, Hadian H. Codifying a Strategic Plan for Academies of the Iranian Volleyball Federation using a SWOT-AHP Method. Ann Appl Sport Sci. 2017:0-0.

7. Aghaei A, Naderian Jahromi M, Memari J, Andam R. Pathology Of Handball Province Using The Model Of Strategic Planning. Sport Manag Rev. 2013;10(17):13-41.

8. Nazari V, Razavi S, Hoseini S. The Design and codification of the strategic plan beach volleyball in Iran. Sport Manag Stud. 2016;6(27):63-86.

9. Baladi M. Design and codification of a strategic plan for the development of martial arts based on the SWOT model for years 1396-1392- Case study: Isfahan province. Tehran: Tehran Branch, Payam Noor University; 2014

10. Khabiri M, Memari J, Arabameri E, Elahi A. Strategies and Macroplans in the Development of Iran's Taekwondo. Res Sport Sci. 2010(27):33-46.

11. Khabiri M, Me'mari J. Iranian Taekwondo SWOT Analysis. Sport Manag Rev. 2012;9(15):13-30.

12. English Karate Council. English Karate Council Development Plan 2014 - 2018 UK: English Karate Council; 2018 [cited 2018]. Available from: https://bit.ly/2OoVJag.

13. Ghasemzadeh Mircolaee E. Studying the reasons for the failure and unsustainability of executing Iran's national athletics talent-identification model. Appl Res Sport Manag Biol. 2015;4(14):35-47.

14. Ghafouri F, Rahmansersht H, Kouzehchian H, Ehsani M. A Study About Physical Educators Beliefs In TheEffects Of The Mass Media On Social Trends Towards Sport For All And Elite Sport. Harakat. 2003(16):57-78.

15. Khabiri M. The Study Of Ethical Conducts Between Athlete And Non-Athlete Females. Harakat. 2002(13):5-20. 